\title{
Effects of Peer Victimization on School Adjustment of Fourth Grade Elementary School Children in Multi- Cultural Families: The Moderated Mediating Effect of Acculturative Stress by Ego-Resiliency
}

\author{
Eun Gyoung Lee ${ }^{1}$, Sun-Hee Rhee ${ }^{2}$ \\ Researcher, Ewha Institute of Social Sciences, Ewha Womans University, Seoul, Korea ${ }^{1}$ \\ Assistant Professor, Department of Childhood Education, Soongsil Cyber University, Seoul, Korea ${ }^{2}$

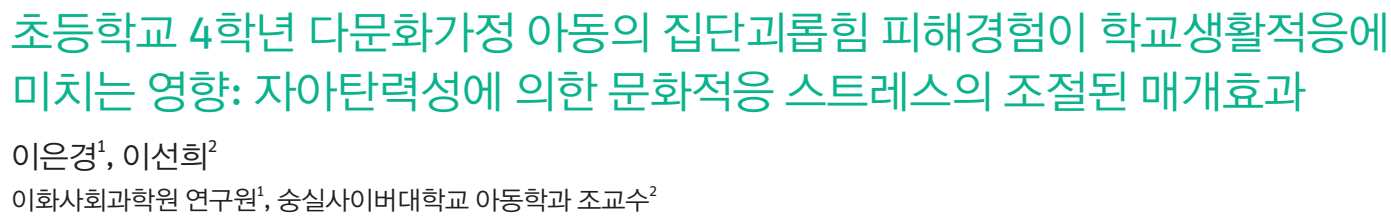

Objectives: This study aimed to investigate the influence of acculturative stress and ego-resiliency on the relationship between peer victimization and school adjustment of children in multi-cultural families. Specifically, the mediating effect of acculturative stress and the moderating effect of egoresiliency were examined in the relationship between peer victimization and school adjustment.

Methods: The research subjects for the first year panel survey conducted by the National Youth Policy Institute were 1,635 children of multi-cultural families completed self-report questionnaires designed to assess peer victimization, acculturative stress, ego-resiliency, and school adjustment. Data were analyzed for the moderated mediating effect between variables using PROCESS Macro methods.

Results: First, acculturative stress partially mediated the relationship between peer victimization and school adjustment. Second, ego-resiliency significantly moderated the relationship between peer victimization and acculturative stress. Namely significantly suggested that peer victimization was more weakly associated with acculturative stress as ego-resiliency was strengthen. Lastly, the mediating effect of acculturative stress was moderated by ego-resiliency in the relation between peer victimization and school adjustment.

Conclusion: Methods are suggested to improve school adjustment of children from multi-cultural families.

Keywords: children in multi-cultural families, peer victimization, ego-resiliency, acculturative stress, school adjustment

\section{Introduction}

현대사회에 이르러 국제화 사회가 되면서 다문화가정의 새로

Corresponding Author: Sun-Hee Rhee, Assistant Professor, Department of Childhood Education, Soongsil Cyber University, 23, Samil-daero 30-gil, Jongno-gu, Seoul, Korea

E-mail: sunny@mail.kcu.ac
운 가족형태가 생겨났고, 다문화가정이 점차 증가하면서 우리 사회의 한 부분을 차지하고 있다. 이러한 현실로 인해 연구자 들은 다문화가정에 관심을 가지기 시작하였다. 초기에는 주

(C)The Korean Association of Child Studies

This is an Open Access article distributed under the terms of the Creative Commons Attribution Non-Commercial License (http:// creativecommons.org/licenses/by-nc/4.0) which permits unrestricted noncommercial use, distribution, and reproduction in any medium, provided the original work is properly cited. 
로 결혼이주여성을 대상으로 한 적응 관련 연구들(A. L. Lee, 2014; S. J. Lee, Park, \& Song, 2014; S. N. Lee \& Lee, 2014)이 이 루어져 왔으나 현재는 다문화가정의 자녀들이 성장하여 학령 기에 접어들면서 이들에 대한 연구의 필요성이 제기되고 있 다. 2017년 교육부 다문화가정 학생 현황에 의하면, 다문화가 정 학생은 10 만 9 천명으로 전년도에 비해 $10.3 \%$ 증가하였고, 우리나라 전체 학령인구는 감소하는 반면, 다문화가정 학생 은 최근 5년간 매년 1만 명 이상 증가하여 2017년 처음으로 10 만 명을 초과하였다. 또한 다문화가정 학생 전체 중, 초등학생 은 $75.7 \%$, 중학생은 $14.6 \%$, 고등학생은 $9.7 \%$ 로 다문화가정 의 자녀들 중 초등학생이 가장 많은 것으로 나타났다(Statistics Korea, 2018). 이러한 통계는 다문화가정의 초등학생 자녀들에 게 관심을 갖고 연구할 필요성을 제기한다.

이와 같이, 최근 몇 년 동안 교육현장에서 다문화가정 아동 의 비율이 증가함에 따라 이들의 학교생활적응에 대한 관심이 증가하고 있다. 학교생활적응이란 학교생활에 관심을 가지고 편안하게 적응에 성공하는 정도를 의미하는 것으로, 학교 환 경의 요구에 따라 자신을 변화시킴으로써 학교 환경과의 균형 을 이루며 또래나 교사와의 대인관계에서 적절한 행동을 하여 만족스러운 학교생활을 하는 것을 말한다(Ladd, Kochenderfer, $\&$ Coleman, 1996). 다문화가정 자녀들은 매년 증가하고 있는 실정이지만 이들은 비다문화가정 자녀들에 비해 학교 이탈자 가 많고 상급 진학률이 저조한 것으로 나타나 학교생활적응 에 어려움을 보인다(H. Kim \& Moon, 2013). 특히 다문화가정 초등학생들은 언어문제, 빈곤, 차별 등으로 인해 학교생활적 응에 어려움을 보였으며, 이로 인해 학업성취 수준도 비다문 화가정 아이들에 비해 크게 떨어지는 것으로 나타났다(H.-S. Chung et al., 2016). 2015년 전국 다문화가족 실태조사에 따르 면, 다문화가정 초등학생들은 학년이 올라가면서 교과내용을 이해하고 학교수업을 따라가는데 어려움을 보이고, 고학년으 로 올라갈수록 교사와의 관계가 점점 악화되는 것으로 보고되 고 있다. 또한 친구와 어울리지 못하고 공부가 어려워지면서 학교를 중도 포기하는 다문화가정 학생들도 발견되는 것을 볼 때(H.-S. Chung et al., 2016), 다문화가정 초등학생들이 학교생 활적응을 잘 할 수 있도록 도와야 할 필요가 있다. 이를 위해 다문화가정 초등학생들의 학교생활적응에 영향을 미치는 예 측변인들을 살펴보고 그들의 학교생활적응을 돕고자 한다.

다문화가정 초등학생들의 학교생활적응에 영향을 미치는 변인 중 먼저 또래관계에 대해 고려할 필요가 있다. 초등학교 고학년 시기는 부모의 영향력에서 점점 벗어나 또래와의 관계 를 중요시하고 학교생활에 열중하는 시기이다. 이 시기에 또
래, 교사 등과의 대인관계 형성은 아동의 건강과 행복에 필수 적인 요소로, 아동의 행복지수가 높을수록 학교생활적응도 가 높아지는 것을 볼 때(E.-S. Hyun \& Hwang, 2019), 다문화가 정 아동의 또래관계 형성이 학교생활적응에 미치는 영향에 대 해 살펴볼 필요가 있다. 학년이 높아질수록 친구와의 안정적 애착은 정서적 친밀감을 형성하여 학교생활적응에 도움을 주 는 반면, 또래와 친밀한 관계를 형성하지 못하는 아동은 안정 적인 사회적 지지원을 찾지 못해 학교생활 부적응을 보이게 된 다(Parker \& Asher, 1987). 특히 또래집단 안에서의 집단괴롭힘 경험은 다문화가정 초등학생의 학교생활적응에 부정적 영향 을 주는 위험요인으로 작용한다(Lim, 2018; Shim, 2009). 집단 괴롭힘은 두 명 이상이 집단을 이루어 특정인을 그가 속한 집 단 속에서 소외시켜 구성원으로서의 역할수행에 제약을 가하 거나 인격적으로 무시 혹은 음해하는 언어적 - 신체적인 일체 의 행위를 의미한다(O. B. Chung, 2017). 학교 내 집단괴롭힘은 다문화가정 자녀들이 비다문화가정 자녀들에 비해 2배 넘게 경험하고 있는 것으로 보고되고 있으며(I. Oh, 2014), 주로 다 른 피부색, 언어능력의 부족, 문화의 차이 등으로 인해 또래로 부터 괴롭힘을 받는 경우가 많다(O. B. Chung, 2017). 집단괴롭 힘 경험은 아동의 심리적 건강을 해칠 뿐 아니라 학교를 회피 하고 낮은 학업성취를 보이는 등 학교생활 부적응 문제를 야기 하는 요인으로 작용한다(Y.-A. Jang, 2014; Schwartz \& Gorman, 2005). 다문화가정 초등학생을 대상으로 집단괴롭힘과 학교생 활적응 간의 관계를 살펴본 연구에서도 다문화가정 초등학생 들의 집단괴롭힘 경험은 교사관계 및 친구관계(Lim, 2018), 학 업능력(Shim, 2009)에 부정적 영향을 미치고, 학교생활 만족도 (H. J. Jeong, 2011)를 낮추는 것으로 보고되었다.

또한 다문화가정 아동은 가정과 사회환경 속에서 문화적 차이와 그로 인한 충돌을 직간접적으로 경험하면서 문화적응 스트레스를 받고 있다. 다문화가정의 자녀들이 경험하는 문화 적응 스트레스는 또래로부터 소외감이나 차별감을 느끼게 하 기 때문에 건강한 성장과 발달을 저해하며 더 나아가 학교생 활 부적응에 영향을 미치게 된다. 따라서 다문화가정 초등학 생의 학교생활적응에 부정적 영향을 미치는 또 다른 위험요인 으로 문화적응 스트레스를 고려해 볼 수 있다. 문화적응 스트 레스(accultuartion stress)란 개인이나 집단 이주자들이 새로운 사회의 문화에 적응하는 과정에서 경험하는 스트레스 현상을 의미한다(Hovey \& Magaña, 2002). 브론펜브레너의 생태학적 이론에 의하면, 거시체계에 속하는 문화는 개인의 행동이나 생활에 영향을 주는 것으로, 인간은 태어나면서부터 신념, 규 범, 가치 등을 자신이 속한 문화 안에서 배워나간다고 하였다. 
이 때, 자신의 문화와 다른 형태의 문화에 접촉하게 되는 경우, 개인의 행동, 태도, 가치 등의 다양한 심리적 변화과정을 겪으 며 문화적응을 해나가야 한다(Redfield, Linton, \& Herscovits, 1936). 문화적응은 새로운 문화적 양식에 자극을 받고 오랜 시간에 걸쳐 일어나는 변화과정으로, 다른 문화에 적응하기 까지 다양한 자극들에 의해 스트레스를 경험하게 된다(Berry, 1997). 다문화가정 자녀들은 태어나면서부터 서로 다른 문화 에서 성장한 부모에게 양육을 받으면서 이중 문화를 경험하 게 되고 이로 인해 문화적응의 어려움을 겪는다(M. K. Kim \& $\mathrm{Kim}, 2015)$. 이중 문화의 적응과정에서 취약한 권력에 놓여있 는 다문화가정 자녀들은 한국 문화의 동화를 요구받게 되며 이중 언어 유창성의 압박과 부정적 편견 등으로 문화적응 스 트레스를 경험하게 된다(Jiang \& Bae, 2018). 이러한 문화적응 스트레스는 낮은 자존감, 불안감, 정체성 혼란을 불러일으키 고(Barrett, Sonderegger, \& Sonderegger, 2002), 심리적 문제는 결 국 다문화 초등학생들의 학교생활 부적응에 영향을 미치는 것 으로 보고된다(J. A. Oh, 2019). 다문화가정 학생들을 대상으 로 부모애착과 학교생활적응 관계에서 문화적응 스트레스가 매개하는지를 검증한 연구에서 문화적응 스트레스는 부분매 개 하는 것으로 나타나 문화적응 스트레스가 다문화가정 초등 학생의 학교생활적응에 부정적 영향을 미치는 것으로 나타났 다(Choi \& Hong, 2018). 비슷한 맥락에서 문화변용 스트레스 를 높게 느끼는 초등학생들은 학급 내 활동성, 학습관련 태도 및 행동 수준이 낮은 것으로 나타났다(Rhee, 2016).

또한 또래관계가 중요해지는 초등학교 고학년들에게 의미 있는 타인과 관계를 맺는 것은 중요한 발달과업 중 하나이다 (Dubow \& Ullman, 1989). 문화적응 스트레스 역시 개인을 둘 러싼 환경에 의해 영향을 받는 것을 볼 때, 문화적응 스트레스 에 영향을 주는 요인으로 또래관계와 같은 사회적 지지를 고 려해볼 수 있다. 실제로, 다문화가정 아동이 또래와 긍정적 관 계를 맺거나 또래로부터 지지를 받을수록 문화적응 스트레스 수준이 낮아지는(M. Jeong, 2018) 반면, 또래로부터 고립되거 나 무시되는 등 또래에게 인정받지 못하는 경우에는 문화적 응 스트레스가 높아지는 것으로 나타났다(Shin \& Youn, 2010). 다문화가정 아동들이 외국적인 외모차이로 인해 또래집단에 게 집단따돌림을 경험하게 되면 높은 문화적응 스트레스를 보 이는 것으로 보고되고 있다(J. M. Hong, 2009). 또한 또래괴롭 힘을 경험한 아동이 높은 스트레스를 경험한다는 기존연구 (Jang, 2019)를 통해 또래로부터의 따돌림을 받거나 괴롭힘을 당한 경험들은 문화적응 스트레스로 이어질 것으로 유추해볼 수 있다.
한편, 자아탄력성은 고난, 역경, 상실을 경험하는 상황에서 유연하고 융통성 있게 적응하고 스트레스를 잘 극복할 수 있 는 일종의 성격유형으로(J. H. Block \& Block, 1980), 어렵거나 힘든 상황에서 긍정적 적응을 유발하는 심리적 구인이다. 따 라서 자아탄력성은 다문화가정 아동이 환경적·발달적 위험요 인에 노출될 경우 그러한 위험요인을 해석하는 방식에 영향 을 미치며 사회적 적응에 영향을 주게 된다. 이에, 자아탄력성 은 또래로부터 괴롭힘을 경험한 다문화가정 아동들에게 이 를 극복할 수 있는 보호요인으로 작용한다(Lim, 2018; Wegner, Garcia-Santiago, Nishimura, \& Hishinuma, 2010). 탄력적인 아 동은 또래괴롭힘 상황에서도 상황에 맞게 대처하는 능력이 뛰 어난 반면, 비탄력적인 아동은 상황에 적응하는 능력이 떨어 져 부정적 정서를 경험하게 된다(W. J. Park, 2011). 또한 자아 탄력성과 또래괴롭힘 간의 구조적 관계를 살펴본 연구에서는 자아탄력적인 집단에서 또래관계를 보다 적응적으로 잘 하고 친구 간 문제 해결전략을 다양하게 사용하는 것으로 나타나 (Han \& Kim, 2013), 높은 자아탄력성은 또래관계 어려움을 극 복하도록 도와주었다.

또한 자아탄력성이 높은 아동들은 스트레스 상황에서 자신 의 긴장 수준을 약화시키는 조절능력이 높기 때문에 변화하는 상황적 요구들에 있어서 성공적인 적응을 할 수 있는 반면, 자 아탄력성이 낮은 아동은 낮선 상황에 반응하는 융통성이 부 족하기 때문에 효율적인 대처능력이 부족하다(J. H. Block \& Block, 1980; Klohnen, 1996). 자아탄력성이 자신의 스트레스 상황을 잘 극복할 수 있도록 도와주는 변인임을 고려해 볼 때, 자아탄력성의 수준에 따라 다문화가정 아동의 문화적응 스트 레스에 주는 영향은 서로 다르다. 예를 들어, 자아탄력성이 높 은 다문화가정 아동은 문화적응 스트레스를 잘 극복하지만 자 아탄력성이 낮은 다문화가정 아동은 문화적응 스트레스가 높 은 것으로 나타났다(An, 2019).

이러한 연구결과를 토대로, 다문화가정 아동이 또래집단 내에서 괴롭힘을 경험하더라도 높은 자아탄력성을 지니고 있 으면 융통성 있고 유연하게 상황을 대처할 수 있기 때문에 자 신이 경험하는 문화적응 스트레스를 보다 잘 극복할 수 있게 됨을 유추해 볼 수 있다. 이는 집단괴롭힘 피해경험과 자아탄 력성의 조절효과를 통해 문화적응 스트레스에 영향을 줄 수 있음을 짐작하게 한다. 그러나 기존 선행연구들은 자아탄력성 이 또래괴롭힘과 문화적응 스트레스에 각각 어떤 영향을 미치 는지 살펴본 연구만 있을 뿐, 세 변인 간의 관련성을 살펴본 연 구는 찾아보기 어려운 실정이다. 따라서 본 연구에서는 다문 화가정 아동의 집단괴롭힘 피해경험과 문화적응 스트레스 간 
의 관계에서 이들의 관계가 자아탄력성에 의해 조절되는지 살 펴보고자 한다.

위에서 살펴본 선행연구들을 통해 다문화가정 아동의 집단 괴롭힘 피해경험과 문화적응 스트레스, 학교생활적응간의 관 계는 다문화가정 아동이 집단괴롭힘 피해경험을 많이 할수록 문화적응 스트레스를 높게 지각하게 함으로써 학교생활적응 의 어려움이 증가하는 것을 가정할 수 있다. 이와 더불어 다문 화가정 아동의 자아탄력성이 높을수록 집단괴롭힘 피해경험 을 잘 극복하여 문화적응 스트레스를 줄임으로써 문화적응 스 트레스가 학교생활적응에 미치는 부정적 영향이 완충됨을을 예측해볼 수 있다. 그러나 지금까지 다문화가정 아동을 대상 으로 학교생활적응을 살펴본 기존연구들은 학교생활적응과 단일요인 간의 관계를 분석하는 수준에 그쳤으며, 특히 학교 생활적응과 관련 있는 변인들 간에 조절된 매개효과를 검증한 연구는 미미한 실정이다.

종합해보면, 본 연구에서는 종속변수로 학교생활적응을 설 정하고 이에 영향을 미치는 변인으로 집단괴롭힘 피해경험, 문화적응 스트레스, 자아탄력성 간의 관계를 알아보고자 하였 다. 구체적으로 집단괴롭힘 피해경험이 학교생활적응으로 연 결되는 과정에서 문화적응 스트레스가 매개역할을 하는지, 그 리고 집단괴롭힘 피해경험이 문화적응 스트레스에 영향을 미 치는 데 있어서 자아탄력성이 조절역할을 하는지 탐색하였다. 또한 집단괴롭힘 피해경험과 학교생활적응의 관계에서 자아 탄력성이 문화적응 스트레스의 매개효과를 조절하는지 검증 하였다. 본 연구의 연구문제와 연구모형은 Figure 1과 같다.

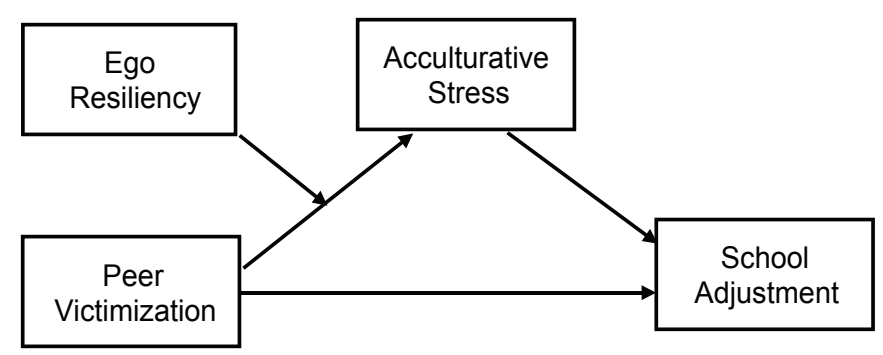

Figure 1. Study model.

\section{연구문제 1}

다문화가정 아동의 문화적응 스트레스는 집단괴롭힘 피해경 험과 학교생활적응의 관계를 매개하는가?

\section{연구문제 2}

다문화가정 아동의 자아탄력성은 집단괴롭힘 피해경험과 문 화적응 스트레스의 관계를 조절하는가?

\section{연구문제 3}

다문화가정 아동의 집단괴롭힘 피해경험과 학교생활적응의 관계에서 자아탄력성은 문화적응 스트레스의 매개효과를 조 절하는가?

\section{Methods}

\section{연구대상}

본 연구는 한국청소년정책연구원에서 수행한 다문화청소 년 패널조사(Multicultural Adolescents Panel Study [MAPS])연 구의 1 차년도 초등학교 4 학년 데이터를 활용하였다. 본 연 구대상은 남학생 805 (49.2\%)명, 여학생 830 (50.8\%)명으로 총 1,635 명으로 구성되었으며, 아버지가 외국인인 경우는 69 (4.2\%)명, 어머니가 외국인인 경우는 1,561 (95.2\%)명, 부모 모두 외국인인 경우 5 (0.3\%)명으로 대부분 어머니가 외국 인인 것으로 나타났다. 외국인 어머니의 출신국가는 일본이 528 (32.3\%)명, 필리핀이 401 (24.5\%)명, 조선족 중국인 323 (19.8\%)명으로 나타났다. 또한 부모와 학생 사이의 의사소통 시 사용언어는 한국어로만 사용하는 경우가 975 (59.6\%)명, 대부분 한국어를 사용하면서 외국인 부모의 말을 약간 사용 하는 경우가 $406(24.8 \%)$ 명으로 나타났다. 다음으로 다문화가 정 아동의 거주지역은 경인권이 452 (27.6\%)명, 경상권이 369 (22.6\%)명, 전라 및 제주도가 325 (19.9\%)명 순으로 나타났다.

연구대상을 초등학교 4학년으로 선정한 이유는 일반적으 로 아동이 초등학교 4학년에 접어들면서 저학년보다 학교에 머무는 시간이 길어지고, 또래 순응성이 증가하면서 친구에게 수용되는 정도가 중요해지며, 학업의 난이도가 어려워지면서 학교생활적응에 대한 문제가 아동의 안녕과 행복감에 상당한 영향을 미치기 때문이다(Compas, Hinden, \& Gerhardt, 1995; Y.-A. Park, 2014).

\section{연구도구}

\section{집단괴롭힘 피해경험}

다문화청소년 패널조사에서는 다문화가정 아동의 집단괴롭 힘 피해경험을 알아보기 위해 H. K. Lee와 Kim (2001)의 집단 괴롭힘 경험을 묻는 척도 중 피해경험 문항만을 수정·보완하 여 사용하였다. 이 척도는 6 문항으로 구성되었으며, 전혀 그렇 
지 않다(1점)에서 매우 그렇다(4점)까지 4점 리커트 척도로 점 수가 높을수록 집단괴롭힘의 피해경험이 많은 것을 의미한다. 문항의 예로는 “나는 다른 학생들로부터 따돌림을 당했다.”를 들 수 있다. 문항의 내적 신뢰도는 .88로 나타났다.

\section{자아탄력성}

다문화청소년 패널조사에서는 다문화가정 아동의 자아탄력 성을 측정하기 위해 J. Block과 Kreman (1996)이 개발한 자아 적응 유연성(ego-resiliency scale)을 Yoo와 Shim (2002)이 수정. 보완한 문항을 Kwon (2003)이 재인용하여 수정한 J. K. Kim, Back, Im과 Lee (2010)의 문항을 발췌하여 사용하였다. 이 척도 는 14 문항으로 구성되었으며, 전혀 그렇지 않다(1점)에서 매 우 그렇다(4점)까지 4점 리커트 척도로 점수가 높을수록 자아 탄력성이 높은 것을 의미한다. 문항의 예로는 "나는 갑자기 놀 라는 일을 당해도 금방 괜찮아지고 그것을 잘 이겨낸다.”를 들 수 있다. 문항의 내적 신뢰도는 .89로 나타났다.

\section{문화적응 스트레스}

다문화청소년 패널조사에서는 다문화가정 아동의 문화적응 스 트레스를 측정하기 위해 Hovey와 King (1996)이 개발한 Social, Attitudinal, Familial and Environmental Acculturative Stress Scale for Adolescents (SAFE) 척도를 수정하여 사용한 Noh (2000)의 문항을 수정한 J. J. Hong (2003)의 문항을 사용하였다. 이 척도 는 10 문항으로 구성되었으며, 전혀 그렇지 않다(1점)에서 매우 그렇다(4점)까지 4점 리커트 척도로 점수가 높을수록 문화적 스트레스가 높은 것을 의미한다. 문항의 예로는 "다른 사람이 외국인 부모님 나라의 문화를 갖고 농담할 때 스트레스를 받는 다.”를 들 수 있다. 문항의 내적 신뢰도는 .85로 나타났다.

\section{학교생활적응}

다문화청소년 패널조사에서는 다문화가정 아동의 학교생활 적응을 측정하기 위해 $\operatorname{Min}$ (1991)이 개발한 학교생활 척도를 Jeong (2009, 재인용)이 수정 · 보완한 J. K. Kim 등(2010)의 학 교적응 척도 가운데 MAPS에서 학교생활적응과 관련된 변인 으로 제시한 교우관계 적응(4문항)과 학습활동 학교적응 $(5$ 문 항), 교사와의 관계 적응( 5 문항)의 변인을 하나의 변인으로 합 산하여 사용하였다. 이 척도는 전혀 그렇지 않다(1점)에서 매 우 그렇다(4점)까지 4점 척도로 구성되어 있으며 "나는 친구
의 일을 방해한다.”와 “나는 공부시간에 딴 짓을 한다.”의 2 문 항을 역채점하였고, 점수가 높을수록 교우관계, 학습활동, 교 사와의 관계에 잘 적응하고 있는 것을 의미한다. 문항의 예로 는 "나는 우리 반 아이들과 잘 어울린다."를 들 수 있다. 문항 의 내적 신뢰도는 .87 로 나타났다.

\section{자료분석}

본 연구의 자료분석은 SPSS 22.0 (IBM Co., Armonk, NY)와 SPSS Process Macro (Hayes, 2013)를 이용하였다. 첫째, 연구대 상자의 인구통계학적 특성(성비, 부/모가 외국인 경우, 외국인 어머니의 출신국가, 부모와의 상호작용 시 사용하는 언어)을 알아보기 위해 빈도분석을 실시하였다. 둘째, 측정도구들의 신 뢰도를 위해 문항 간 내적합치도 Cronbach's $\alpha$ 의 값을 산출하 였다. 셋째, 측정변인들 간의 관련성을 알아보기 위해 상관관 계 분석을 실시하였다. 넷째, 매개효과를 검증하기 위해 Process Macro 4 모형을, 조절효과를 검증하기 위해 Process Macro 1 모 형을 이용하여 검증하였다. 조절효과가 유의하게 판단되어 Johnson-Neyman 기법으로 조절변수의 유의미한 범위를 구하 고, Aiken과 West (1991)의 제안에 따라 독립변인과 조절변인 각각의 평균으로부터 $\pm 1 S D$ 인 지점을 선으로 연결하여 도식화 함으로써 두 변인의 상호작용 양상을 살펴보았다. 마지막으 로 Process Macro 7 모형을 이용하여 조절된 매개변인을 분석하 였다. 이 때 조절변수의 수준에 따른 매개효과의 유의성을 검 증하기 위해 연구모형의 측정오차를 반영하는 부트스트래핑 (bootstrapping)방법을 사용하였으며, Process Macro의 결과에 나타난 모든 효과는 표준화 계수( $\beta$ )보다 비표준화 계수 $(B)$ 가 자료를 정확하게 반영한다는 Hayes (2013)의 제안에 따라 본 연구에서는 모든 효과를 비표준화 계수 $(B)$ 로 보고하였다.

\section{Results}

\section{집단괴롭힘 피해경험과 문화적응 스트레스, 자아탄력성, 학교생활적응 간의 관계}

먼저 자료의 정규분포성을 확인하기 위해 KolmogorovSmirnov와 Shapiro-Wilk 검증을 한 결과 유의수준 .05에서 자료 의 점수가 정규분포를 따르는 것으로 나타났다. 각 변인들의 일반적 경향성을 알아보기 위해 평균을 살펴보면 점수의 범위 가 1-4점임을 고려할 때, 집단괴롭힘 피해경험과 문화적응 스 
Table 1

Correlations Among the Variables

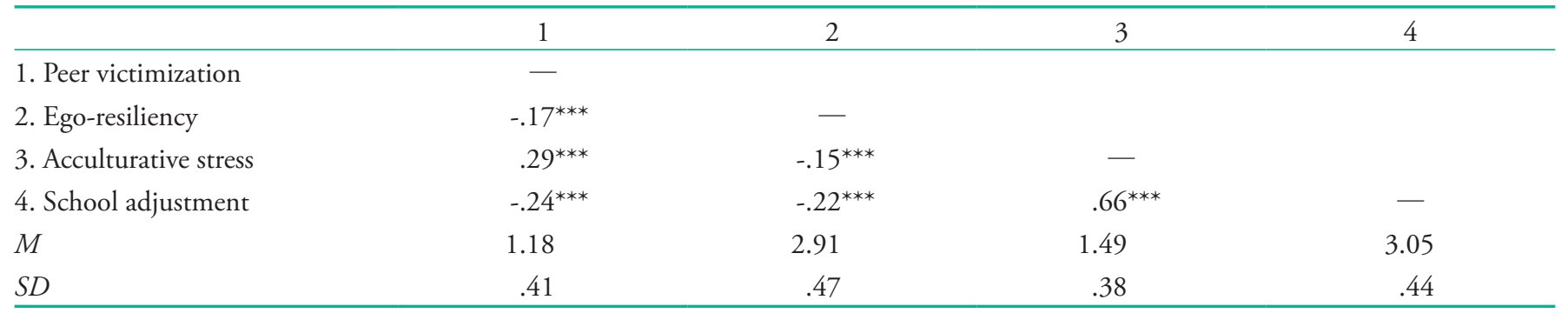

Note. $N=1,635$.

*** $p<.001$.

Table 2

Mediating Effect of Acculturative Stress Between Peer Victimization and School Adjustment

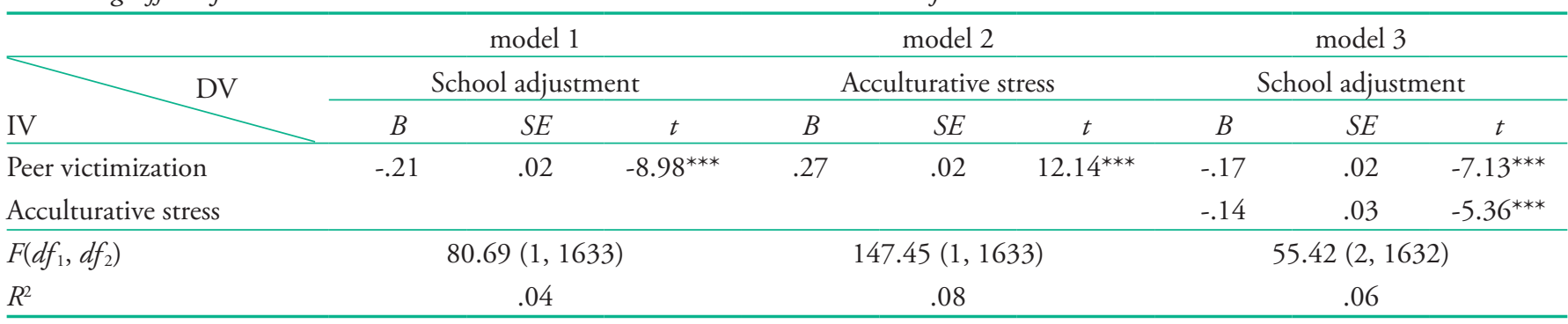

Note. $N=1,635$.

${ }^{* * *} p<.001$.

트레스는 낮은 수준으로, 자아탄력성과 학교생활적응은 높은 수준으로 나타났다.

다음으로 다문화가정 아동의 집단괴롭힘 피해경험과 문화 적응 스트레스, 자아탄력성, 학교생활적응 간의 관계를 알아 보기 위해 상관분석을 실시한 결과, 모든 변인들 사이에 상관 이 있는 것으로 $(r=-.17 \sim .66)$ 나타났다(Table 1$)$. 즉, 다문화가 정 아동의 집단괴롭힘 피해경험이 높은 것과 문화적응 스트레 스를 많이 받는 것은 학교생활적응을 잘 하지 못하는 것과 관 련이 있었으며, 자아탄력성이 높은 것은 집단괴롭힘 피해 경 험이 적은 것과 문화적응 스트레스는 적게 받는 것, 학교생활 적응을 잘 하는 것과 관련이 있는 것으로 나타났다.

\section{집단괴롭힘 피해경험과 학교생활적응 간의 관계에서 문화적응 스트레스의 매개효과}

다문화가정 아동의 집단괴롭힘 피해경험이 문화적응 스트레 스를 통해 학교생활적응에 영향을 미치는지를 알아보기 위하 여 Process Macro 4 model을 활용하여 매개효과 분석을 실시하 였다. 그 결과 모형 1 에서 다문화가정 아동의 집단괴롭힘 피해 경험은 학교생활적응에 유의미한 영향을 미쳤고 $(B=-.21, p<$
.001), 모형 2에서 문화적응 스트레스에 대해서도 유의미한 영 향을 미쳤다 $(B=.27, p<.001)$. 모형 3에서 매개변인인 문화적응 스트레스는 학교생활적응에 유의한 영향을 미쳤으며 $(B=-.14$, $p<.001)$, 집단괴롭힘이 학교생활적응에 미치는 영향력은 모형 1 에 비해서는 감소하였지만 여전히 유의한 것으로 나타났다 $(B$ $=-.17, p<.001)$. 이러한 결과는 다문화가정 아동의 집단괴롭힘 피해경험이 학교생활적응에 미치는 영향을 문화적응 스트레스 가 부분적으로 매개하고 있음을 나타낸다(Table 2).

다음으로 다문화가정 아동의 집단괴롭힘의 피해경험과 학 교생활적응의 관계에서 문화적응 스트레스의 매개효과의 크 기가 통계적으로 유의미한지를 검증하기 위해 부트스트래핑을 실시한 결과 $(B=-.04, S E=01, \mathrm{CI}[-.06,-.02])$ 로 신뢰구간에서 0 을 포함하고 있지 않아 효과크기가 유의미한 것으로 나타났다.

\section{집단괴롭힘 피해경험과 문화적응 스트레스 간의 관계에서 자아탄력성의 조절효과}

다문화가정 아동의 집단괴롭힘 피해경험이 문화적응 스트레 스에 미치는 영향을 자아탄력성이 조절하는지를 알아보기 위 하여 Process Macro 1 모형을 활용하여 조절효과 분석을 실시 
Table 3

Moderating Effect of Ego-Resiliency Between Peer Victimization and Acculturative Stress

\begin{tabular}{|c|c|c|c|c|c|c|c|}
\hline & \multirow[b]{2}{*}{$B$} & \multirow[b]{2}{*}{$S E$} & \multirow[b]{2}{*}{$t$} & \multicolumn{2}{|c|}{$95 \% \mathrm{CI}$} & \multirow[b]{2}{*}{$F\left(d f_{1}, d f_{2}\right)$} & \multirow[b]{2}{*}{$R^{2}$} \\
\hline & & & & $\mathrm{LL}$ & UL & & \\
\hline Peer victimization $(\mathrm{A})$ & .27 & .02 & $11.58^{* * *}$ & .22 & .32 & $59.15^{* * *}(3,1631)$ & .09 \\
\hline$A \times B$ & .09 & .03 & $2.64^{* *}$ & .02 & .16 & & \\
\hline
\end{tabular}

Note. $N=1,635$.

${ }^{*} p<.05 .{ }^{* * *} p<.001$.

Table 4

Significance of the Simple Slopes

\begin{tabular}{|c|c|c|c|c|c|}
\hline \multirow[b]{2}{*}{ Ego-resiliency } & \multirow[b]{2}{*}{$B$} & \multirow[b]{2}{*}{$S E$} & \multirow[b]{2}{*}{$t$} & \multicolumn{2}{|c|}{$95 \%$ CI } \\
\hline & & & & LL & UL \\
\hline$-1 S D$ & .23 & .03 & $9.23^{* * *}$ & .18 & .28 \\
\hline 0 & .27 & .02 & $11.58^{* * *}$ & .23 & .32 \\
\hline$+1 S D$ & .31 & .03 & $9.89^{* * *}$ & .25 & .37 \\
\hline
\end{tabular}

Note. $N=1,635$.

${ }^{* *} p<.01 .{ }^{* * *} p<.001$.

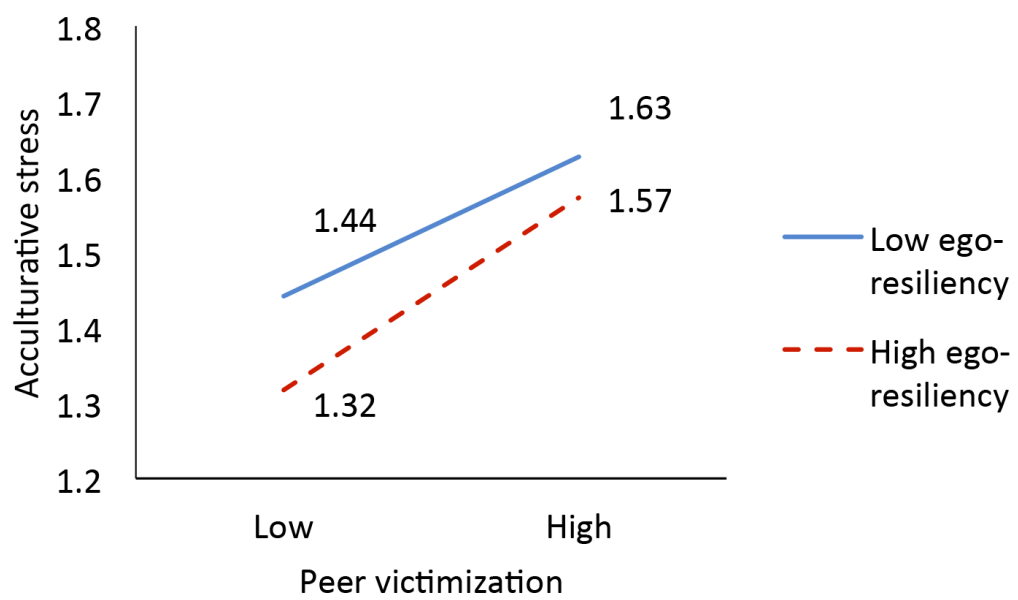

Figure 2. Interactional effect of peer victimization and ego-resiliency on acculturative stress.

하였다. 그 결과 Table 3에 나타난 바와 같이 다문화가정 아동 의 문화적응 스트레스에 대한 집단괴롭힘 피해경험과 자아탄 력성 그리고 이 두 변인의 상호작용의 설명량은 $9.81 \%$ 로 나타 났다 $(F=59.15(3,1631), p<.001)$. 다음으로 다문화가정 아동 의 집단괴롭힘 피해경험과 자아탄력성의 상호작용 효과가 유 의미함에 따라 $(B=.09, p<.01)$, Johnson-Neyman 기법으로 조 절변수의 유의미한 범위를 산출하였다. 그 결과 자아탄력성이 $.31 \%$ 99.69\%에 해당하는 $1.18 \sim 4.00$ 까지 조절효과가 유의 미한 범위로 확인되었다.

다음으로 다문화가정 아동의 자아탄력성 수준에 따른 효과
크기를 산출하였다. 그 결과 자아탄력성이 낮은 집단(-1SD)에 서 효과크기 $B=-.23(t=9.23, p<.001,95 \%$ CI $[.18, .28])$, 자 아탄력성이 높은 집단 $(+1 S D)$ 에서 효과크기 $B=-.31(t=9.89$, $p<.001,95 \% \mathrm{CI}[.25, .37])$ 로 신뢰구간에서 0을 포함하고 있 지 않아 효과크기가 유의미한 것으로 나타났다(Table 4, Figure 2). 즉, 다문화가정 아동이 집단괴롭힘의 피해경험을 많이 할 수록 문화적응 스트레스를 많이 경험하는 것으로 나타났으나 이 때 자아탄력성이 높은 집단보다 낮은 집단에서 더 문화적 응 스트레스를 많이 경험하는 것을 의미한다. 
Table 5

Moderated Mediating Effect of Acculturative Stress by Ego-Resiliency

\begin{tabular}{|c|c|c|c|c|c|c|c|}
\hline & \multicolumn{7}{|c|}{ DV: Acculturative stress } \\
\hline & \multirow[b]{2}{*}{$B$} & \multirow[b]{2}{*}{$S E$} & \multirow[b]{2}{*}{$t$} & \multicolumn{2}{|c|}{$95 \% \mathrm{CI}$} & \multirow[b]{2}{*}{$F\left(d f_{1}, d f_{2}\right)$} & \multirow[b]{2}{*}{$R^{2}$} \\
\hline & & & & LL & UL & & \\
\hline Ego-resiliency (B) & -.10 & .02 & $-4.83^{* * *}$ & -.13 & -.06 & & \\
\hline \multirow[t]{3}{*}{$A \times B$} & .09 & .03 & $2.64^{* *}$ & .02 & .16 & & \\
\hline & & & & \multicolumn{2}{|c|}{$95 \% \mathrm{CI}$} & & \\
\hline & $B$ & $S E$ & $t$ & $\mathrm{LL}$ & UL & $F\left(d f_{1}, d f_{2}\right)$ & $R^{2}$ \\
\hline Peer victimization & -.17 & .02 & $-7.13^{* * *}$ & -.22 & -.12 & $55.41^{* * *}(2,1632)$ & .06 \\
\hline Acculturative stress & -.14 & .03 & $-5.36^{* * *}$ & -.19 & -.09 & & \\
\hline
\end{tabular}

Note. $N=1,635$.

${ }^{* *} p<.01 .{ }^{* * *} p<.001$.

Table 6

Significance of the Moderated Mediating Effect

\begin{tabular}{|c|c|c|c|c|c|c|}
\hline & & \multirow[b]{2}{*}{$B$} & \multirow[b]{2}{*}{$S E$} & \multirow[b]{2}{*}{$t$} & \multicolumn{2}{|c|}{$95 \% \mathrm{CI}$} \\
\hline & & & & & LL & UL \\
\hline & Direct effect & -.17 & .02 & $-7.13^{* * *}$ & -.22 & -.12 \\
\hline \multirow{2}{*}{ Indirect effect } & Ego-resiliency 0 & -.04 & .01 & & -.06 & -.02 \\
\hline & Ego-resiliency $+1 S D$ & -.04 & .01 & & -.06 & -.02 \\
\hline
\end{tabular}

Note. $N=1,635$. Indirect effect $=$ peer victimization $\rightarrow$ acculturative stress $\rightarrow$ school adjustment.

*** $p<.001$.

\section{집단괴롭힘 피해경험이 학교생활적응에 미치 는 영향에서 자아탄력성에 의한 문화적응 스 트레스의 조절된 매개효과}

다문화가정 아동의 집단괴롭힘 피해경험과 학교생활적응 간 의 관계에서 문화적응 스트레스의 매개효과와 집단괴롭힘 피 해경험과 문화적응 스트레스 간의 관계에서 자아탄력성의 조 절효과를 확인한 결과 매개효과와 조절효과 모두 통계적으로 유의미함을 확인하였다. 이와 동시에 다문화가정 아동의 집단 괴롭힘 피해경험과 학교생활적응 간의 관계에서 자아탄력성 의 조절효과가 통계적으로 유의미하지 않았으므로, 조절된 매 개효과 분석을 위한 모든 가정이 충족되었다. 다음으로 다문 화가정 아동의 집단괴롭힘이 문화적응 스트레스의 매개효과 를 통해 학교생활적응으로 미치는 영향에 있어서 자아탄력성 의 조절된 매개효과를 검증하기 위해 Process Macro 7 model을 활용하여 분석하였다. 그 결과 독립변인인 다문화가정 아동의
집단괴롭힘 피해경험은 매개변인인 문화적응 스트레스에 정 적으로 영향을 미치는 것으로 나타났다 $(B=.27, p<.001)$. 그 리고 문화적응 스트레스가 종속변인인 학교생활적응에 미치 는 영향이 통계적으로 유의미한 것으로 나타났다 $(B=.14, p<$ .001). 또한 다문화가정 아동의 집단괴롭힘 피해경험과 자아 탄력성의 상호작용이 문화적응 스트레스에 미치는 영향 역시 유의미한 것으로 확인되었다 $(B=.09, p<.01)$. 이는 다문화가 정 아동의 집단괴롭힘 피해경험과 학교생활적응 사이에서 문 화적응 스트레스의 매개효과는 자아탄력성의 수준에 따라 달 라진다는 것을 의미한다(Table 5).

다문화가정 아동의 자아탄력성의 문화적응 스트레스에 대 한 조절된 매개효과의 크기와 신뢰구간을 확인하기 위해 부트 스트랩을 실시하였다. 즉, 다문화가정 아동의 자아탄력성의 평균 $-1 S D$ 집단, 평균집단, $+1 S D$ 수준에서 모두 $95 \%$ 신뢰구 간에 0이 포함되지 않아 통계적으로 유의미한 결과를 확인하 였다(Table 6). 구체적으로 살펴보면 다문화가정 아동의 자아 
탄력성이 낮을 때 $(B=-.03, S E=01,95 \% \mathrm{CI}[-.05,-.02])$ 보다 자 아탄력성이 높을 때 $(B=-.04, S E=01,95 \% \mathrm{CI}[-.06,-.02])$ 집단 괴롭힘 피해경험이 문화적응 스트레스를 통해 학교생활적응 에 미치는 간접효과 영향의 크기가 더 작게 나타났다(Table 6). 따라서 다문화가정 아동의 자아탄력성이 높을수록 문화적응 스트레스의 간접효과가 작아지는 것을 의미한다. 즉, 다문화 가정 아동의 자아탄력성이 높은 경우 집단괴롭힘 피해경험을 하더라도 문화적응 스트레스 증가로 인한 학교생활적응의 감 소가 완화된다.

\section{Discussion}

본 연구는 초등학교 4학년에 재학 중인 다문화가정 남녀 아동 을 대상으로 집단괴롭힘 피해경험이 학교생활적응에 미치는 영향을 확인하고 그 관계에서 문화적응 스트레스의 매개효과 를 검증하기 위해 시행되었다. 또한 개인 내적 변인인 자아탄 력성이 집단괴롭힘 피해경험과 문화적응 스트레스 관계를 조 절하는지 살펴보았으며, 집단괴롭힘 피해경험과 학교생활적 응 관계에서 자아탄력성이 문화적응 스트레스의 매개효과를 조절하는지 검증하였다. 본 연구의 연구문제를 토대로 결과를 요약하고 논의하면 다음과 같다.

첫째, 다문화가정 아동의 집단괴롭힘 피해경험과 문화적 응 스트레스는 학교생활적응을 예측하는 유의미한 요인이며, 특히 집단괴롭힘 피해경험은 문화적응 스트레스를 부분매개 로 학교생활적응에 영향을 주는 것으로 확인되었다. 즉, 집단 괴롭힘 피해경험이 직접적으로 학교생활적응에 영향을 미치 기도 하며, 문화적응 스트레스를 통해 간접적으로도 학교생 활적응에 영향을 미쳤다. 이는 또래로부터 괴롭힘을 받는 아 동은 학교생활 만족도가 떨어지고 등교를 거부하는 등 학교생 활 부적응을 경험한다는 선행연구들과(Jang, 2014; H. J. Jeong, 2011; S. S. Kim, 2008; Kochenderfer-Ladd, 2004; Lim, 2018; Nishina \& Juvonen, 2005), 문화적응 스트레스가 높을수록 학 교생활적응에 어려움을 보인다고 밝힌 선행연구들(Choi \& Hong, 2018; Rhee \& Lee, 2016; Sim, Lee, \& Park, 2013)과 일치 하는 결과이다. 즉, 또래관계의 중요성이 강조되는 시기에 또 래괴롭힘 경험은 다문화가정 아동들의 문화적응 스트레스를 불러일으키고, 그 결과 친구, 교사와의 관계 및 학업성취를 어 렵게 하여 학교생활 적응에 부정적 영향을 미치는 것으로 해 석된다. 이는 또래괴롭힘의 피해 정도가 높을수록 스트레스를 더 많이 받고, 높은 스트레스는 수업활동, 친구 및 교사와의 적
응을 어렵게 만든다는 연구결과와 유사하다(Jang, 2014). 이러 한 연구결과를 통해 학교생활 부적응을 보이는 다문화가정 아 동들의 문제를 해결하기 위해서는 집단 괴롭힘을 극복하고 한 국 문화에 적응할 수 있도록 도울 필요가 있다. 다문화가정 아 동에게 도움을 주는 어른이 있는 경우 집단따돌림 피해를 입 은 학생들이 다시 학교에 잘 적응한다는 연구결과(Lim, 2018) 에 근거할 때, 담임교사, 각종 청소년 시설 선생님, 지역사회 의 성인들 등의 사회적 지지가 필요함을 알 수 있다. 이와 더불 어, 다문화가정 아동의 건강한 발달과업 수행을 위해서 그들 이 이중문화에 대한 정체성을 통합시키는데 관심을 가져야한 다. LaFromboise, Coleman과 Gerton (1993)의 이중문화주의 이 론에 따르면 이중문화를 경험하는 경우, 유연한 문화적응을 위해서는 주류문화와 비주류문화 중 어느 한쪽의 일방적인 동 화가 아닌 두 문화의 정체성을 통합하는 방식으로 이루어져야 한다. 실제로 다문화가정 아동이 자신의 이중문화에 대한 가 치와 신념을 수용하고, 이중 언어를 활용하며 이중문화의 역 할수행을 유연하게 했을 때 문화적응 스트레스가 낮은 것으로 나타났다. 따라서 다문화가정 아동들이 문화탐방과 같은 문화 적응 훈련프로그램에 참여할 수 있도록 독려하고 다문화 이해 교육을 통해 문화적응 유연성을 지닐 수 있도록 도와야 한다. 또한 다문화 아동의 문화적응을 효과적으로 돕기 위해서 이들 의 문화적응 스트레스를 지속적으로 추적 관리하고 그들의 문 화적응 스트레스의 발달적 특성과 개인차를 이해하여 개별화 된 지원을 해야 할 필요가 있다.

둘째, 다문화가정 아동의 자아탄력성이 집단괴롭힘 피해경 험과 문화적응 스트레스의 관계를 조절하는지 분석한 결과 자 아탄력성의 조절효과는 자아탄력성이 높은 집단과 낮은 집단 모두에서 유의한 것으로 나타났다. 이를 구체적으로 살펴보면 다문화가정 아동의 집단괴롭힘 피해경험은 문화적응 스트레 스를 높이는 것으로 나타났으나 이 때 자아탄력성이 높은 집단 보다 낮은 집단에서 문화적응 스트레스를 더 많이 경험하고 자 아탄력성이 낮은 집단보다 높은 집단에서는 문화적응 스트레 스를 덜 받는 것으로 나타났다. 이는 다문화가정 아동의 자아 탄력성이 높은 경우 집단괴롭힘 피해경험이 문화적응 스트레 스에 미치는 부정적 효과를 완충해주는 역할을 한다고 볼 수 있다. 이러한 연구결과는 자아탄력성이 높은 다문화가정 아동 이 또래관계를 능숙하게 하고(Lim, 2018), 친구 간 문제가 발생 했을 때 다양한 전략을 사용하여(Han \& Kim, 2013) 다문화가 정 아동의 문화적응 스트레스(M. Jeong, 2018)를 완충해준다는 연구결과와 같은 맥락으로 이해해 볼 수 있다. 이는 자아탄력 적인 아동은 또래관계를 맺는 데 있어서 융통성 있게 행동하고 
개인의 감정을 조절하며 적극적으로 문제를 분석하기 때문에 또래괴롭힘을 극복하여 문화적응 스트레스를 덜 경험하는 것 으로 해석된다. 다문화가정 아동들은 이중 정체성을 경험하면 서 문화 부적응을 겪게 되는데, 이 때 개인에 따라 이러한 상황 에 쉽게 좌절되는 아동이 있는가 하면 유연하게 적응함으로써 그것을 이겨낼 수 있는 아동이 있다. 이러한 차이는 자아탄력 성에 따라 달라지는 것으로, 변화하는 환경에 융통성 있게 적 응할 수 있도록 자아탄력성을 증진시켜 준다면 다양한 문화적. 사회적 배경을 이해하는 능력이 확장되어 문화적응 스트레스 를 감소시키는 데 도움이 될 수 있다. 따라서 다문화가정 아동 의 자아탄력성을 높여주기 위한 노력으로, 부모는 자녀가 지닌 어려움을 스스로 극복할 수 있도록 기다리고 인내해야 하며, 자녀가 자신의 실패에 대한 두려움을 이기고 문제를 적극적으 로 해결할 수 있는 힘을 키울 수 있도록 안내해야 한다.

셋째, 조절된 매개효과를 분석한 결과 다문화가정 아동의 집단괴롭힘 피해경험과 학교생활적응의 관계에서 문화적응 스트레스의 매개효과와 집단괴롭힘 피해경험과 문화적응 스 트레스의 관계에서 자아탄력성의 조절효과를 확인한 결과 매 개효과와 조절효과 모두 통계적으로 유의미하게 나타났다. 이 와 동시에 집단괴롭힘 피해경험과 학교생활적응의 관계에서 자아탄력성의 조절효과가 통계적으로 유의미하지 않았기 때 문에 조절된 매개효과를 확인하였다. 즉, 본 연구에서 나타난 조절된 매개효과는 다문화가정 아동이 또래괴롭힘 피해경험 이 있다 하더라도 높은 자아탄력성을 통해 완충됨으로써 자아 탄력성이 낮은 집단 보다 높은 집단에서 문화적응 스트레스를 덜 받게 되어 학교생활에 잘 적응하는 것을 의미한다. 이를 통 해, 다문화가정 아동의 문화적응 스트레를 감소시켜 주고 학 교생활 적응을 잘 할 수 있도록 돕기 위해서는 다문화가정 아 동의 자아탄력성을 증진시켜 주는 것이 필요함을 확인하였다. 이는 Kumpfer (2002)의 탄력성 구조 모형에서 스트레스가 적 응에 미치는 영향력이 개인 내적인 요인들에 의해 달라질 수 있음을 의미하는 것으로, 심리적 보호요인으로서 자아탄력성 의 중요성을 지지하는 결과이다. 따라서 성인들은 다문화가정 아동이 위험에 직면했을 때 갈등상황에서 유연하게 반응할 수 있도록 도와주고 자신의 감정을 조절하여 융통성 있게 문제를 해결할 수 있도록 지도할 필요가 있다. 즉, 다문화가정 아이들 의 문화적응 스트레스를 줄이고 학교생활 적응을 위해 자아탄 력성을 강화시키기 위한 방안이 함께 모색되어야 한다.

결론적으로, 다문화가정 아동의 문화적응 스트레스가 또래 괴롭힘 피해경험과 학교생활적응을 매개하는 과정에서 또래괴 롭힘 피해경험과 자아탄력성의 상호작용 효과가 문화적응 스
트레스에 영향을 미쳐 학교생활적응에 영향을 주는 것으로 나 타났다. 즉, 다문화가정 아동이 학교 내에서 또래괴롭힘을 경험 하더라도 자아탄력성이 높은 아동은 낮은 아동에 비해 문화적 응 스트레스가 감소하여 결국 학교에서도 잘 적응하게 됨을 확 인하였다. 이는 다문화가정 아동의 학교생활 적응력을 높이기 위해서는 높은 자아탄력성을 지닐 수 있도록 도와야 하고, 문 화적응 스트레스에 영향을 주는 요인들을 감소시켜 이중문화 에 잘 적응할 수 있는 대처기술의 필요성을 시사한다.

본 연구의 제한점과 후속연구를 위한 제언은 다음과 같다. 먼저, 본 연구는 패널데이터를 사용하였기 때문에 측정도구의 문항이 간단하고 대상선정에 한계가 있다. 따라서 다양한 측 정도구를 통한 검증과 대상선정을 확대할 필요가 있다. 또한 본 연구의 결과를 살펴보면 전체적으로 모델의 설명력이 낮게 나타났다. 따라서 추후연구에서는 반복연구를 통해 본 연구에 서 살펴본 경로를 다시 검토해 볼 필요가 있다. 이 외에도, 본 연구에서는 다문화가정 4학년 초등학생을 대상으로 연구하였 으나, 또래관계의 중요성은 중·고등학교 시기에도 여전히 중 요한 것을 고려해 볼 때, 연구대상을 좀 더 확장하여 연구하는 것도 필요하다.

위와 같은 제한점에도 불구하고 본 연구는 몇 가지 의의가 있다. 먼저, 다문화가정 아동의 학교생활적응에 영향을 미치 는 주요 변인들의 관계를 지금까지 연구된 바가 없는 조절된 매개효과를 살펴보았다는 데 의의가 있다. 다음으로, 높은 자 아탄력성은 또래괴롭힘 피해경험과 상호작용하여 문화적응 스트레스를 감소시켜 학교생활을 잘 할 수 있도록 이끄는 변 인임을 확인하였다. 본 연구는 다문화가정 아동의 따돌림이나 학교폭력 등의 문제가 심각해지고 있는 현 시점에서 다문화가 정 아동의 학교생활 적응력을 높일 수 있는 프로그램 개발 및 개입 방향을 위한 기초자료로 활용될 수 있을 것이다.

\section{Acknowledgements}

This work was supported by the Ministry of Education of the Republic of Korea and the National Research Foundation of Korea (NRF-2016S1A3A2924375).

\section{Conflict of Interest}

No potential conflict of interest relevant to this article was reported. 


\section{References}

\section{In English}

Aiken, L. S., \& West, S. G. (1991). Multiple regression: Testing and interpreting interactions. Thousand Oaks, CA: Sage.

Barrett, P. M., Sonderegger, R., \& Sonderegger, N. L. (2002). Assessment of child and adolescent migrants to Australia: A crosscultural comparison. Behaviour Change, 19(4), 220235. doi:10.1375/bech.19.4.220

Berry, J. W. (1997). Immigration, acculturation, and adaptation. Applied Psychology, 46(1), 5-34. doi:10.1111/j.14640597.1997.tb01087.x

Block, J. H., \& Block, J. (1980). The role of ego-control and egoresiliency in the origination of behavior. In W. A. Collins (Ed.), Development of cognition, affect and social relations: The Minnesota symposia on child psychology (pp. 39-101). Mahwah, NJ: Lawrence Erlbaum Associates.

Block, J., \& Kremen, A. M. (1996). IQ and ego-resiliency: Conceptual and empirical connections and separateness. Journal of Personality and Social Psychology, 70(2), 349-361. doi:10.1037/0022-3514.70.2.349

Compas, B. E., Hinden, B. R., \& Gerhardt, C. A. (1995). Adolescent development: Pathways and processes of risk and resilience. Annual Review of Psychology, 46(1), 265-293.

Dubow, E. F., \& Ullman, D. G. (1989). Assessing social support in elementary school children: The survey of children's social support. Journal of Clinical Child Psychology, 18(1), 52-64. doi:10.1207/s15374424jccp1801_7

Hayes, A. F. (2013). Introduction to mediation, moderation, and conditional process analysis: A regression-based approach. New York: Guilford Press.

Hovey, J. D., \& King, C. A. (1996). Acculturative stress, depression, and suicidal ideation among immigrant and secondgeneration Latino adolescents. Journal of the American Academy of Child and Adolescent Psychiatry, 35(9), 11831192. doi:10.1097/00004583-199609000-00016

Hovey, J. D., \& Magaña, C. G. (2002). Psychosocial predictors of anxiety among immigrant Mexican migrant farm workers: Implications for prevention and treatment. Cultural Diversity and Ethnic Minority Psychology, 8(3), 274-289. doi:10.1037/1099-9809.8.3.274

Klohnen, E. C. (1996). Conceptual analysis and measurement of the construct of ego-resiliency. Journal of Personality and Social Psychology, 70(5), 1067-1079. doi:10.1037/00223514.70.5.1067

Kochenderfer-Ladd, B. (2004). Peer victimization: The role of emotions in adaptive and maladaptive coping. Social Development, 13(3), 329-349. doi:10.1111/j.1467$9507.2004 .00271 . x$
Kumpfer, K. L. (1999). Factors and processes contributing to resilience. In M. D. Glantz, \& J. L. Johnson (Eds.) Resilience and development (pp. 179-224). NY: Kluwer Academic/Pienum Publishers.

Ladd, G. W., Kochenderfer, B. J., \& Coleman, C. C. (1996). Friendship quality as a predictor of young children's early school adjustment. Child Development, 67(3), 1103-1118. doi: $10.2307 / 1131882$

LaFromboise, T., Coleman, H. L., \& Gerton, J. (1993). Psychological impact of biculturalism: Evidence and theory. Psychological Bulletin, 114(3), 395-412.

Nishina, A., \& Juvonen, J. (2005). Daily reports of witnessing and experiencing peer harassment in middle school. Child Development, 76(2), 435-450. doi:10.1111/j.14678624.2005.00855.x

Parker, J. G., \& Asher, S. R. (1987). Peer relations and later personal adjustment: Are low-accepted children at risk? Psychological Bulletin, 102(3), 357-389. doi:10.1037//00332909.102.3.357

Redfield, R., Linton, R., \& Herscovits, M. J. (1936). Memorandum for the study of acculturation. American Anthropologist, 38(1), 149-152.

Schwartz, D., \& Gorman, A. H. (2005). Victimization in the peer group and children's academic functioning. Journal of Educational Psychology, 97(3), 425-435. doi:10.1037/00220663.97.3.425

Wegner, E., Garcia-Santiago, O., Nishimura, S. T., \& Hishinuma, E. S. (2010). Educational performance and attitude toward school as risk-protective factors for violence: A study of the Asian/Pacific island youth violence prevention center. Psychology in the Schools, 47(8), 789-802. doi:10.1002/ pits. 20504

\section{In Korean}

An, H. J. (2019). Moderating effect of ego-resilience and social support on the relationship between multi-cultural adolescents's acculturative stress and life satisfaction. Journal of Learner-Centered Curriculum and Instruction, 19(12), 789-807. doi: 10.22251/jlcci.2019.19.12.789

Choi, K., \& Hong, J. (2018). The relationship between parental attachment and school adjustment in adolescents of multicultural families: The mediating effects of cultural adaptation stress. Studies on Korean Youth, 29(1), 347-374. doi:10.14816/sky.2018.29.1.347

Chung, H.-S., Kim, Y.-S., Yi, T., Ma K. H., Choi, Y., Park G., Dong, C., ... Lee, E. (2016). An analysis on the national survey of multicultural families 2015 (Report No. 2016-03). Retrieved from Ministry of Gender Equality and Family website: http://www.mogef.go.kr 
Chung, O. B. (2017). Sahoejeongseobaldal [사회정서발달]. Seoul: Hakjisa.

Han, E.-S., \& Kim, C.-K. (2013). A structural analysis between related variables of peer bullying by elementary school students: Mediating effect of ego-resiliency. Korean Journal of Counseling, 14(6), 3307-3322. doi:10.15703/ kjc.14.6.201312.3307

Hong, J. J. (2003). A study on psychosocial adaptation of youth in Mongolian migrant workers' family (Master's thesis). Retrieved from http://www.riss.kr/link?id=T9285465

Hong, J. M. (2009). Ecological variable affecting adjustment to school life of children from multi-cultural families (Doctoral dissertation). Retrieved from http://www.riss.kr/ link?id=T11577721

Hyun, E.-S., \& Hwang, H.-J. (2019). The effect of teacher attachment, peer attachment on happiness of late elementary school students: Focusing on the mediating effect of school life adaptaion. Journal of Learner-Centered Curriculum and Instruction, 19(5), 451-472. doi:10.22251/jlcci.2019.19.5.451

Jang, Y.-A. (2014). A effect of adolescent's peer bulling and victimization on stress and school Adjustment. Youth Facilities and Environment, 12(3), 85-93.

Jeong, H. J. (2011). A study on the children's educational environment, self-esteem, and adaptation to schools in multicultural families of rural areas: A comparison with the children from nonmulticultural families (Doctoral dissertation). Retrieved from http://www.riss.kr/link?id=T12373192

Jeong, H. S. (2009). The influence of attachment to mother and school life adjustments on elementary school students's optimism (Master's thesis). Retrieved from http://www.riss.kr/ link?id=T11721664

Jeong, M. (2018). The mediated effects of ego resilience among parents-adolescent communication, peer relation, and acculturation stress for middle school students of multicultural families. The Journal of Humanities and Social Science, 9(4), 1455-1470. doi: 10.22143/HSS21.9.4.101

Jiang, H., \& Bae, E.-K. (2018). The relationship between acculturation stress of adolescents in multicultural families and their psychological maladjustment: Focus on the moderating effects of resilience. Journal of the Korean Society of Child Welfare, 62, 131-164. doi: 10.24300/ jkscw.2018.06.62.131

Kim, H., \& Moon, H. (2013). School Adjustment: Comparing children from multicultural families and children of nonmulticultural families. Korean Journal of Social Welfare, 65(4), 7-31.

Kim, J. K., Back, H. J., Im, H. J., \& Lee, G. O. (2010). Korea child.youth panel survey I. Panel Survey Report (Report No. 10-R01). Seoul: National Youth Policy Institute.

Kim, M. K., \& Kim, H. Y. (2015). The effects of psychological characteristics, parent-child relationship, and coping strategies on school adjustment of multicultural family adolescents. Korean Journal of Family Welfare, 20(2), $367-$ 385. doi:10.13049/kfwa.2015.20.2.367

Kim, S. S. (2008). A study on the school adjustment, friendship quality and children's adjustment according to peer victimization (Master's thesis). Retrieved from http://www. riss.kr/link?id=T11592587

Kwon, J. E. (2003). The relation of ego-resilience, parent and peer attachment, and problem-solving (Master's thesis). Retrieved from http://www.riss.kr/link?id=T8586513

Lee, A. L. (2014). The a case study on the adjustment of family living culture in relation to women who have immigrated through marriage: Vietnamese women in Seoul. Korea Family Resource Management Association, 18(4), 69-90.

Lee, H. K., \& Kim, H. W. (2001). Social and psychological variables predict- ing elementary students' school bullying behaviors: On the bases of their gender and grade. Korean Journal of Social and Personality Psychology, 15(1), 117-138.

Lee, S. J., Park, Y. S., \& Song, J. Y. (2014). The effect of acculturative stress on marital satisfaction of immigrant women who married to Korean men: Focused on the mediation effect of martial communication and social support. Social Science Research Review, 30(4), 1-25.

Lee, S. N., \& Lee, H. S. (2014). Adaptation living in Korea of marriage immigrant women. Journal of Community Welfare, 49, 105-136.

Lim, S. A. (2018). School bullying victims and school adjustment in multicultural adolescents: Examination of the protective roles of ego resilience and adults to help. Journal of Korean Council for Children \& Rights, 22(2), 195-214. doi:10.21459/kccr.2018.22.2.195

Min, B. S. (1991). The effect of school adaptation and self concept on academic performance (Master's thesis). Retrieved from http://www.riss.kr/link?id=T2167733

Noh, C. R. (2000). Use of Rosenberg's self-esteem and collective self-esteem as predicting variables for psychological distress among Korean American adolescents. Journal of the Korean Society of Child Welfare, 10, 107-135.

Oh, I. (2014). Relations between school bullying victimization and psychological problems among students from multicultural families: A focus on mediation effect of psychological wellbeing. Asian Journal of Education, 15(4), 219-238.

Oh, J. A. (2019). Meta-analysis of psycho-social factors and school adaptation of multicultural adolescents. Journal of School Social Work, 45, 159-182. doi:10.20993/jssw.45.7

Park, W. J. (2011). The effect of the ego-resiliency on internalizing and externalizing problems: Mediating effects of cognitive emotion regulation and positive, negative emotion (Doctoral dissertation). Retrieved from http://www.riss.kr/link?id 
$=\mathrm{T} 12398333$

Park, Y.-A. (2014). The influence of ego-resiliency on school adjustment in children: The moderated mediating effect of stress by self-concept. Korean Journal of Child Studies, 35(3), 1-14. doi:10.5723/KJCS.2014.35.3.1

Rhee, J.-Y. (2016). The effect of the acculturation stress of children from multicultural families on school adaptaion. Counseling Psychology Education Welfare, 3(1), 33-39. doi:10.20496/ cpew.2016.3.1.33

Rhee, J.-Y., \& Lee, J.-Y. (2016). The influence of stress for cultural adaptation of mothers of multicultural families on children's emotional and behavioral problems. Counseling Psychology Education Welfare, 3(2), 19-27. doi:10.20496/ cpew.2016.3.2.19

Shim, W.-Y. (2009). Racial identity and psychological attitudes of multicultural students. The Journal of Elementary Education, 22(4), 27-47.

Shin, Y.-J., \& Youn, C.-Y. (2010). Bicultural adjustment, peer relationship and bicultural acceptance attitude of children in multi-cultural family. The Journal of Play Therapy, 14(2), 1-14.

Sim, M. Y., Lee, D. N., \& Park, J. O. (2013). A study of the effect of social support on school adaptation among children from multicultural families: Focused on mediating of

bicultural adaptation. Journal of School Social Work, 25, 233-254.

Statistics Korea. (2018). 2018 cheongsonyeon tonggye [2018 청소년 통계]. Retrieved April 26, 2018, from http://kostat.go.kr/ portal/korea/kor_nw/1/1/index.board?bmode=read $\& b S e$ $\mathrm{q}=\& \mathrm{aSeq}=367381 \&$ pageNo=1 \&rowNum $=10 \&$ navCoun $\mathrm{t}=10 \& \mathrm{currPg}=\&$ searchInfo $=$ srch \&s Target $=$ title \&s $\mathrm{Txt}=\%$ EC\%B2\%AD\%EC\%86\%8C\%EB\%85\%84+\%ED\%86 $\% \mathrm{~B} 5 \% \mathrm{EA} \% \mathrm{~B} 3 \% 84$

Yoo, S. K., \& Shim, H. W. (2002). Psychological protective factors in resilient adolescents in Korea. The Korean Journal of Educational Psycholgy, 16(4), 189-206.

\section{ORCID}

Eun Gyoung Lee Sun-Hee Rhee http://orcid.org/0000-0001-6935-6804

http://orcid.org/0000-0001-8036-2340

Received May 23, 2019 Revision received November 21, 2019 Accepted December 20, 2019 